\title{
Adiantum philippense L. Frond Assisted Rapid Green Synthesis of Gold and Silver Nanoparticles
}

\author{
Duhita G. Sant, ${ }^{1}$ Tejal R. Gujarathi, ${ }^{1}$ Shrikant R. Harne, ${ }^{1}$ Sougata Ghosh, ${ }^{2}$ Rohini Kitture, ${ }^{3}$ \\ Sangeeta Kale, ${ }^{3}$ Balu A. Chopade, ${ }^{1}$ and Karishma R. Pardesi ${ }^{1}$
}

${ }^{1}$ Department of Microbiology, University of Pune, Pune, Maharashtra 411007, India

${ }^{2}$ Institute of Bioinformatics and Biotechnology, University of Pune, Pune, Maharashtra 411007, India

${ }^{3}$ Department of Applied Physics, Defence Institute of Advanced Technology, Girinagar, Pune 411025, India

Correspondence should be addressed to Karishma R. Pardesi; karishma@unipune.ac.in

Received 31 January 2013; Accepted 18 April 2013

Academic Editor: Gunjan Agarwal

Copyright (C) 2013 Duhita G. Sant et al. This is an open access article distributed under the Creative Commons Attribution License, which permits unrestricted use, distribution, and reproduction in any medium, provided the original work is properly cited.

\begin{abstract}
Development of an ecofriendly, reliable, and rapid process for synthesis of nanoparticles using biological system is an important bulge in nanotechnology. Antioxidant potential and medicinal value of Adiantum philippense L. fascinated us to utilize it for biosynthesis of gold and silver nanoparticles (AuNPs and AgNPs). The current paper reports utility of aqueous extract of $A$. philippense L. fronds for the green synthesis of AuNPs and AgNPs. Effect of various parameters on synthesis of nanoparticles was monitored by UV-Vis spectrometry. Optimum conditions for AuNPs synthesis were 1:1 proportion of original extract at $\mathrm{pH} 11$ and $5 \mathrm{mM}$ tetrachloroauric acid, whereas optimum conditions for AgNPs synthesis were $1: 1$ proportion of original extract at $\mathrm{pH}$ 12 and $9 \mathrm{mM}$ silver nitrate. Characterization of nanoparticles was done by TEM, SAED, XRD, EDS, FTIR, and DLS analyses. The results revealed that AuNPs and AgNPs were anisotropic. Monocrystalline AuNPs and polycrystalline AgNPs measured 10 to $18 \mathrm{~nm}$ in size. EDS and XRD analyses confirmed the presence of elemental gold and silver. FTIR analysis revealed a possible binding of extract to AuNPs through $-\mathrm{NH}_{2}$ group and to AgNPs through $\mathrm{C}=\mathrm{C}$ group. These nanoparticles stabilized by a biological capping agent could further be utilized for biomedical applications.
\end{abstract}

\section{Introduction}

Nanotechnology is the study of materials that have at least one dimension in the range of $1-100 \mathrm{~nm}$. Decrease in size is accompanied by elevated surface-area-to-volume ratio. Electronic and chemical properties of a material are dependent on its size. When the bulk material is reduced to nanoscale, its properties change. Such nanomaterials displaying novel properties have effective and wide utility in biological and biomedical applications. Noble metal nanoparticles such as $\mathrm{Au}, \mathrm{Ag}, \mathrm{Pt}$, and Pd have been most effectively studied $[1,2]$.

Physical and chemical methods yield nanoparticles with well-defined shape and size, but these methods are expensive and potentially toxic to environment. This has created a need to develop clean, nontoxic, economical, and environmentally benign methods to synthesize nanoparticles. These concerns have led researchers to develop biological methods for synthesis of nanoparticles.
Castro et al. [3] have reported synthesis of AuNPs, by intracellular or extracellular reduction of tetrachloroauric acid using bacteria. Other biosynthetic routes include fungus, marine sponge, eggshell membrane, whole plant, leaf extract, flower, and tuber extract. Numerous methods available for biosynthesis of AgNPs include bacteria, mushroom, bark, peel extract, and enzyme as reducing agents $[1,4-8]$.

AuNPs are being considered in a wide range of diagnostic and therapeutic applications, such as cancer detection and cancer treatment, drug delivery, biological imaging, and biomedicine, as well as in electrochemistry. The prominent applications of silver nanomaterials include detection and diagnostics, antimicrobials and therapeutics, catalysis, and biolabeling [2].

Integration of phytochemicals in synthesis of nanomaterials is of extreme importance as it brings about integrity of plant science and nanotechnology, termed as green 


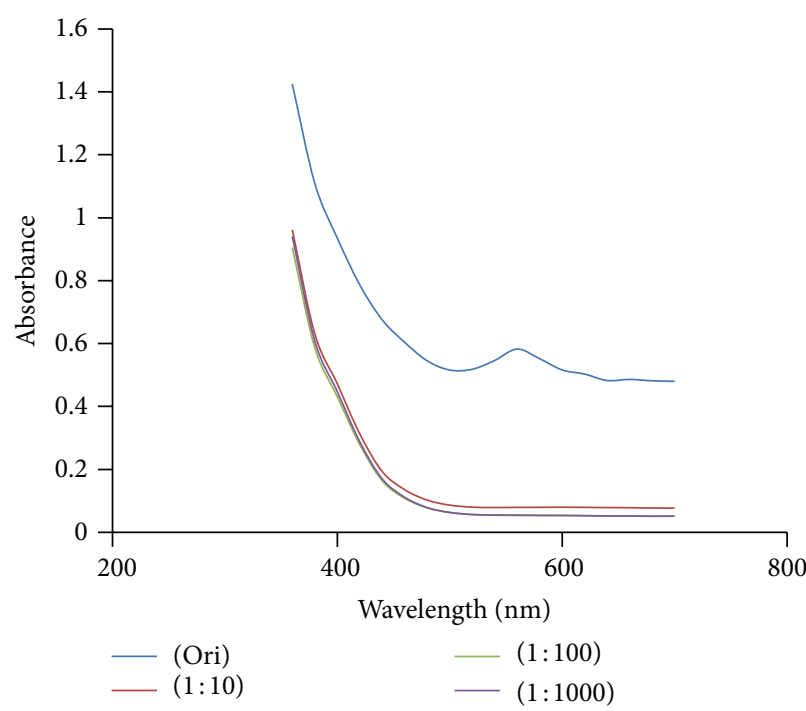

(a)

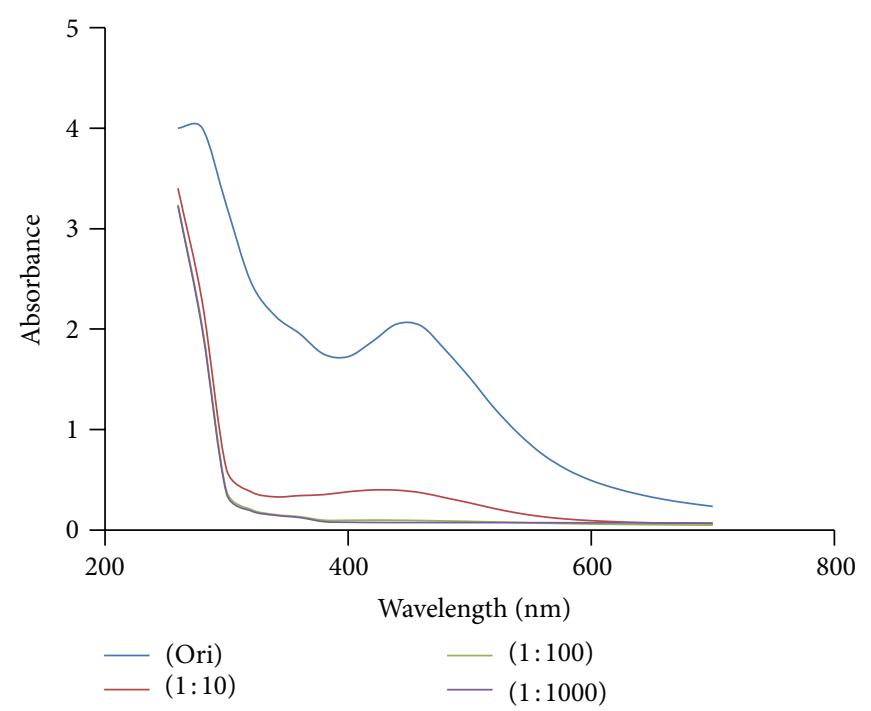

(b)

FIGURE 1: Surface plasmon peaks showing effect of varying extract concentrations (original extract, $1: 10,1: 100$, and $1: 1000$ ) on synthesis of AuNPs (a) and AgNPs (b).

technology. Biosynthesis of nanoparticles using dicotyledonous and monocotyledonous plants has been reported [1]. However, pteridophytes known to man for their use in folk medicine remain unexplored for this purpose.

The fern Adiantum philippense L. (family Adiantaceae) well known for its antioxidant potential [9] has been ethnomedicinally used in treatment of paralysis, blood diseases, epileptic fits, rabies, dysentery, elephantiasis, pimples, and wounds $[10,11]$. It is also known for its antimicrobial activity [11]. Phytochemical analysis of the plant extracts belonging to genus Adiantum shows the presence of carbohydrates, phenols, flavonoids, and terpenoids [11-13]. Therefore, presence of these compounds may have a role in making Adiantum a potential candidate for bioreduction of gold and silver salts. In the present study, we have used A. philippense L. extract for the synthesis of AuNPs and AgNPs.

\section{Material and Methods}

2.1. Preparation of the Aqueous Plant Extract. Fresh fronds of A. philippense L. were obtained from Western Ghats (Sinhagad fort, Pune, India) region and identified from Botanical Survey of India (Western Circle), Pune, India. Fronds with mature sori were washed thoroughly and allowed to dry. Five grams of fronds were chopped into fine pieces and grounded into paste. This paste was extracted in $100 \mathrm{~mL}$ double distilled water. The extract was passed through muslin cloth and filtrate was centrifuged at $2500 \mathrm{~g}$ for $10 \mathrm{~min}$ at room temperature. Supernatant thus obtained was filtered through Whatman Filter Paper No. 1 and used for synthesis of nanoparticles.

2.2. Synthesis of AuNPs and AgNPs. Tetrachloroauric acid salt $\left(\mathrm{HAuCl}_{4} \cdot 4 \mathrm{H}_{2} \mathrm{O}, 49.9 \%\right)$ (SRL Chemicals, India) and silver nitrate salt $\left(\mathrm{AgNO}_{3}, 99.9 \%\right)$ (Qualigen Fine Chemicals, India) were procured and used without any further purification. Aqueous stock solutions of tetrachloroauric acid $(10 \mathrm{mM})$ and silver nitrate $(100 \mathrm{mM})$ were prepared in a stoppered volumetric flask and stored in amber color bottles.

Freshly prepared extract of $A$. philippense L. was mixed with aqueous solution of $10 \mathrm{mM}$ tetrachloroauric acid in $1: 1$ proportion. The mixture was allowed to react at $30^{\circ} \mathrm{C}$, with vigorous shaking. Synthesis of AuNPs was checked visually by determining the color change from yellow brown to dark blue. Similar procedure was followed for synthesis of AgNPs, indicated by a brick red color formation. Confirmation was done on the basis of a characteristic peak obtained in the absorbance range of 500-600 nm for AuNPs and 400$500 \mathrm{~nm}$ for AgNPs.

2.3. Effect of Different Parameters on Synthesis of AuNPs and AgNPs. Effect of different parameters such as concentration of extract (original, $1: 10,1: 100$, and $1: 1000$ in double distilled water), concentration of salt (1-10 mM), and $\mathrm{pH}(2-13)$ of original extract on synthesis of AuNPs and AgNPs was checked. Criterion for selecting optimum condition was observing for a narrow peak at characteristic wavelength giving maximum absorbance.

2.4. Characterization of AuNPs and AgNPs. Absorption spectrum of AuNPs and AgNPs was recorded on (JASCO V630) UV-Vis spectrophotometric multiplate reader. Film Xray diffraction (XRD) was performed using an X-ray diffractometer (Phillips PW1710, Holland) with $\mathrm{CuK} \alpha$ radiation $\lambda=1.5406 \AA$ over a wide range of Bragg angles $\left(20^{\circ} \leq\right.$ $2 \theta \leq 80^{\circ}$ ). Morphology and size of AuNPs were investigated by transmission electron microscopy (Tecnai G ${ }^{2}$ 20U-TWIN (FEI, the Netherlands), TEM with $\mathrm{LaB}_{6}$ electron source) 


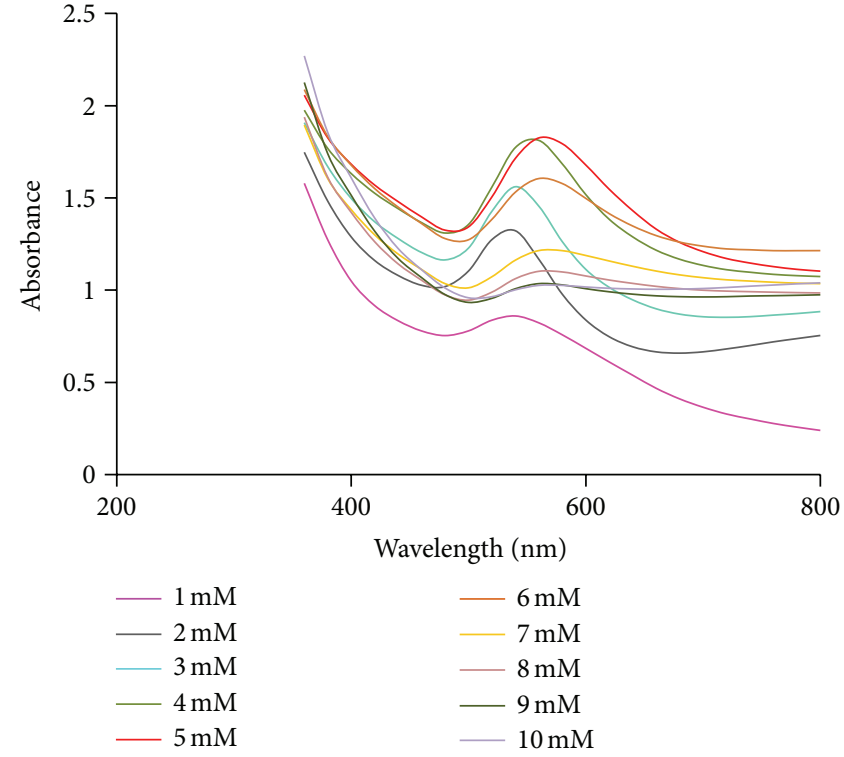

(a)

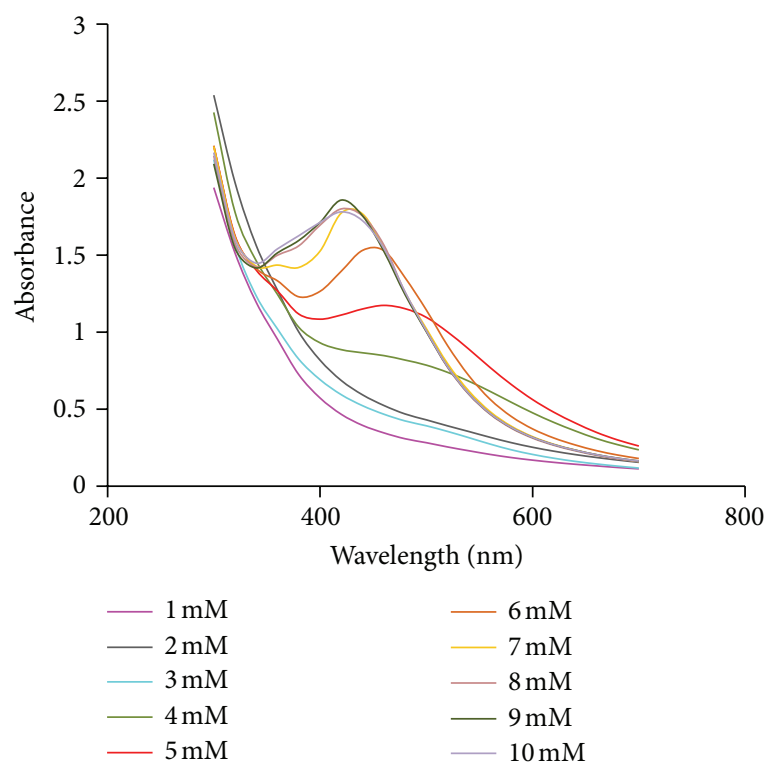

(b)

FIGURE 2: (a) Surface Plasmon Resonance of varying tetrachloroauric acid concentrations (1-10 mM) on synthesis of AuNPs. (b) Surface Plasmon Resonance of varying silver nitrate concentrations (1-10 mM) on synthesis of AgNPs.

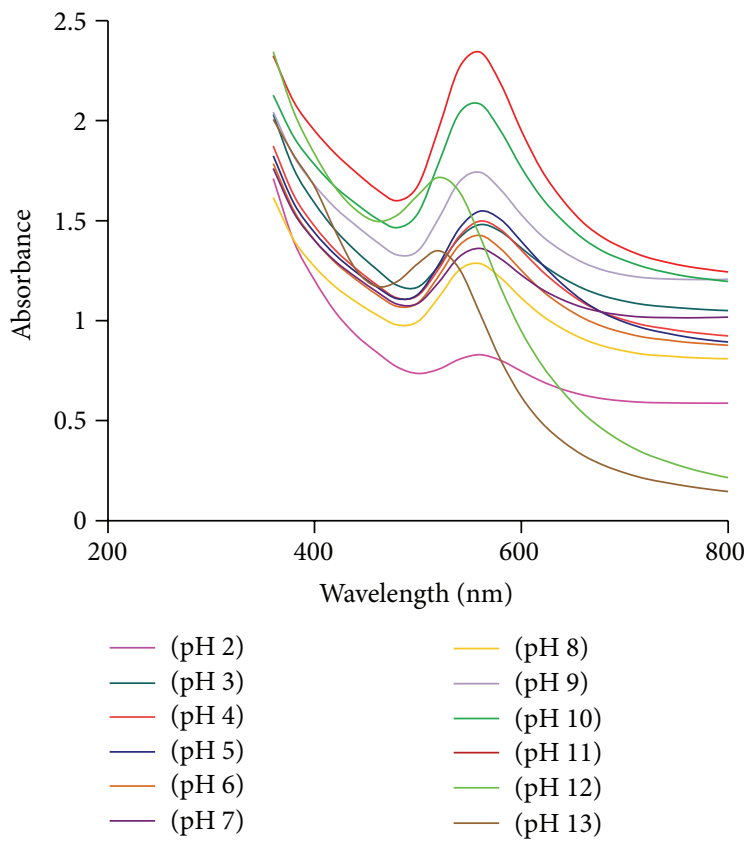

(a)

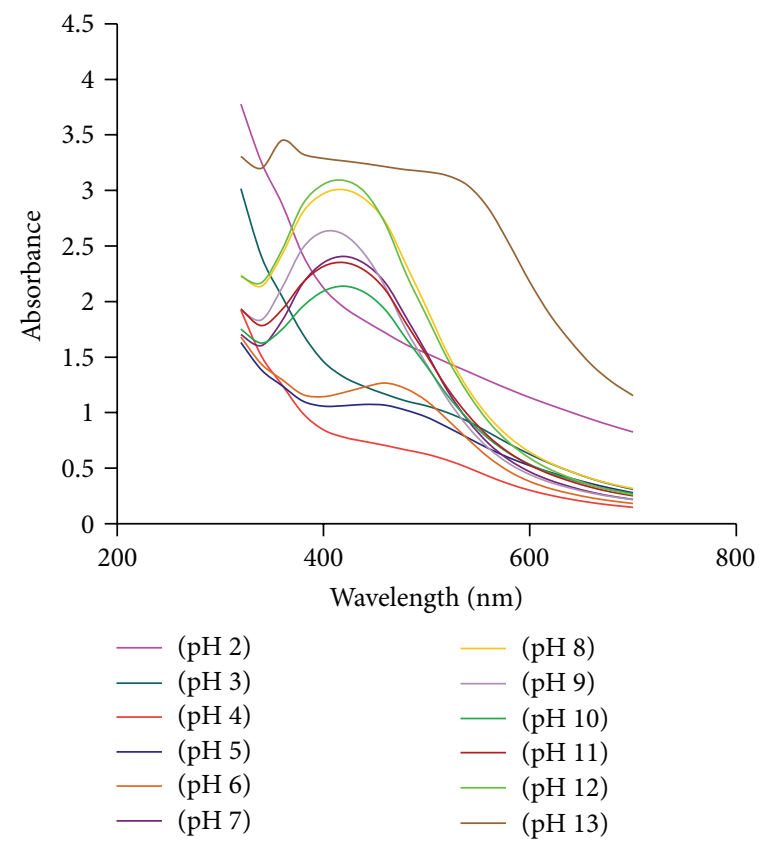

(b)

FIGURE 3: (a) Surface plasmon peaks of AuNPs with varying $\mathrm{pH}$ values (2-13). (b) Surface plasmon peaks of AgNPs with varying pH values $(2-13)$.

with an accelerating voltage of $200 \mathrm{kV}$. An elemental analysis of the sample was examined by energy dispersive analyses of $\mathrm{X}$-rays (EDAX) with 6360 (LA) instrument at an Acc voltage of $20 \mathrm{kV}$. Fourier transform infrared spectroscopic (FTIR) measurements were done using Perkin Elmer (16 PC-FT-IR) spectrophotometer. Particle size distribution was measured by a dynamic light scattering apparatus utilizing $663 \mathrm{~nm}$ red laser at $90^{\circ}$ angles.

The samples for transmission electron microscopy (TEM) and energy dispersive scattering (EDS) and X-ray diffraction (XRD) were prepared by placing a drop of AuNPs and AgNPs onto a $1 \mathrm{~cm} * 1 \mathrm{~cm}$ glass slide. Samples were then heat 
fixed and subjected for analysis. The AuNPs, AgNPs, and A. philippense L. extracts were pelletized separately in IR grade $\mathrm{KBr}$ (HiMedia, India) and were scanned over a range of $4000-400 \mathrm{~cm}^{-1}$ in FTIR analysis.

\section{Results and Discussion}

\subsection{Effects of Various Parameters on Synthesis of $A u N P s$ and $A g N P s$}

3.1.1. Biosynthesis of AuNPs and AgNPs. High antioxidant potential and ethnomedicinal importance of $A$. philippense L. intrigued us to explore it for biosynthesis of AuNPs and AgNPs. Microbial enzymes, polysaccharides, and plant phytochemicals with antioxidant or reducing properties are usually responsible for reduction of metal compounds into their respective nanoparticles $[1,5,14-16]$.

A dark blue color was observed on addition of plant extract to $5 \mathrm{mM}$ tetrachloroauric acid solution indicating AuNPs synthesis. UV-Vis spectroscopy of this solution confirmed the synthesis of AuNPs, as revealed by a characteristic absorption peak at $530 \mathrm{~nm}$ [17]. On the other hand, a characteristic brick red color was formed on addition of $9 \mathrm{mM}$ silver nitrate solution to the plant extract, indicating synthesis of AgNPs, which was confirmed by an absorption peak at $420 \mathrm{~nm}$ [18]. The time for complete reduction of gold and silver ions in solution to nanoparticles was $10 \mathrm{~min}$.

Shankar et al. [19] reported that reduction of the metal ions and stabilization of AuNP or AgNP are due to the presence of terpenoids or alkaloids present in the geranium extract. On the other hand, AuNP synthesis is caused by the reducing sugar present in the lemongrass extract [20]. Similarly, A. philippense L. is known to contain variety of such biologically active phytochemicals like carbohydrates, glycosides, alkaloids, tannins, flavonoids, terpenoids, and saponins. These phytochemicals are responsible for making the extract highly oxidant [12] and thus might play a role in bioreduction of gold and silver nanoparticles.

3.1.2. Effect of Extract Concentration. Various dilutions of plant extract, original $1: 10,1: 100$, and $1: 1000$ (diluted in double distilled water), were analyzed for their effect on synthesis of AuNPs and AgNPs. Original extract ( $5 \mathrm{~g}$ plant biomass in $100 \mathrm{~mL}$ distilled water) showed effective synthesis of nanoparticles with the characteristic color. However, further dilutions of the extract showed negligible synthesis of nanoparticles. UV-Vis spectra suggest that sharpness of absorption peak is dependent on concentration ratio of extract [21]. Accordingly, sharp peak was observed in original extract concentration (Figures 1(a) and 1(b)). There are similar reports showing effect of biomass quantity on synthesis of nanoparticles [22].

3.1.3. Effect of Metal Salt Concentration. Mixing plant extract with increasing concentration of tetrachloroauric acid/silver nitrate ( 1 to $10 \mathrm{mM}$ ) resulted in synthesis of nanoparticles as indicated by an increasing intensity of the characteristic

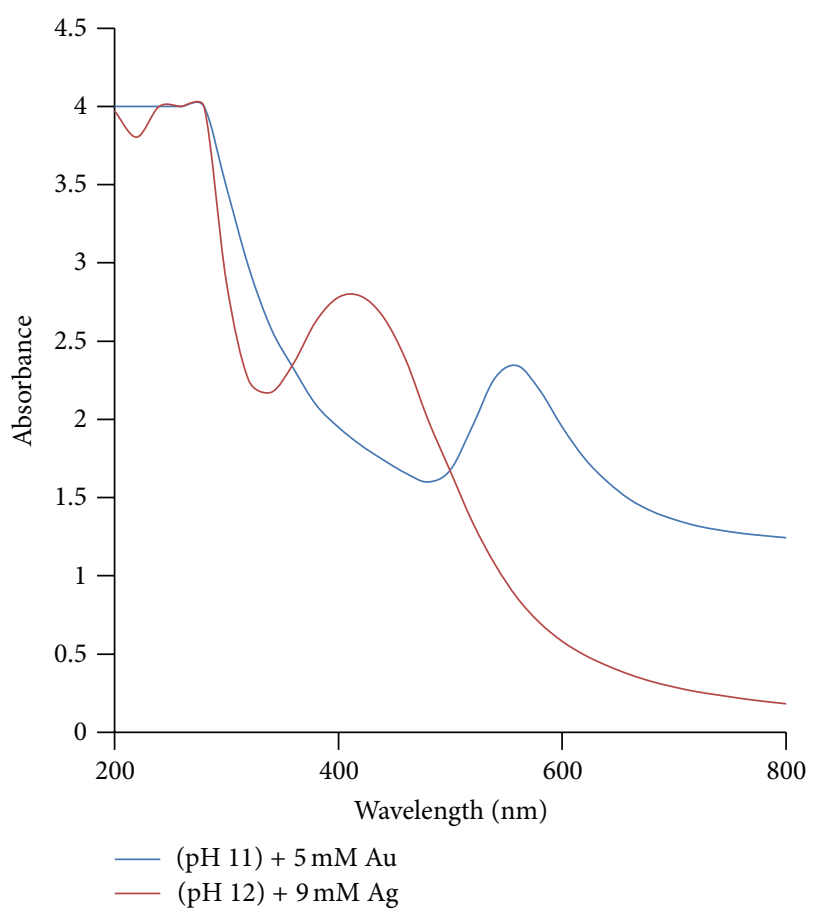

FIGURE 4: SPR at optimum conditions. For Au, original extract at $\mathrm{pH} 11$ and $5 \mathrm{mM}$ tetrachloroauric acid was kept for $10 \mathrm{~min}$. For Ag, original extract at $\mathrm{pH} 12$ and $9 \mathrm{mM}$ silver nitrate was kept for $10 \mathrm{~min}$.

color. In case of AuNPs, peak absorbance increased with tetrachloroauric acid concentration from 1 to $5 \mathrm{mM}$ but decreased at higher metal ion concentrations (Figure 2(a)). Thus, the optimum salt concentration for AuNP synthesis was $5 \mathrm{mM}$, as revealed by a narrow peak at $530 \mathrm{~nm}$. Similar results have been reported by Ghosh et al. [15] with $1 \mathrm{mM}$ tetrachloroauric acid as optimum concentration for AuNP synthesis.

A steady rise in absorbance was also observed for AgNP synthesis using 1 to $10 \mathrm{mM}$ silver nitrate solution. However, there was a marginal difference in absorbance using $9 \mathrm{mM}$ and $10 \mathrm{mM}$ salt concentration as indicated by overlapping peaks in UV-Vis spectra (Figure $2(\mathrm{~b})$ ). This indicates that $9 \mathrm{mM}$ was the optimum concentration for AgNPs synthesis. Other researchers have also reported a significant effect of metal salt concentration on the synthesis of silver nanoparticles $[5,23]$.

3.1.4. Effect of $p H$. Formation of distinct peak depends on concentration of $\mathrm{H}^{+}$ions $(\mathrm{pH})$. Reaction mixtures, containing extract at different $\mathrm{pH}$ units (2 to 13 ) and tetrachloroauric acid solution, showed blue color of varying intensities, indicating formation of AuNPs. UV-Vis spectroscopy further confirmed that a sharp peak obtained at $\mathrm{pH} 11$ was optimum for synthesis of AuNPs (Figure 3(a)).

Similarly for silver, the alkaline $\mathrm{pH}$ range showed brick red color of varying intensities indicating the synthesis of AgNPs. UV-Vis spectrum confirmed a sharp peak at $\mathrm{pH} 12$, to be optimum (Figure 3(b)). At lower $\mathrm{pH}$, nanoparticles show lower and broader absorbance which can be due to larger size. 


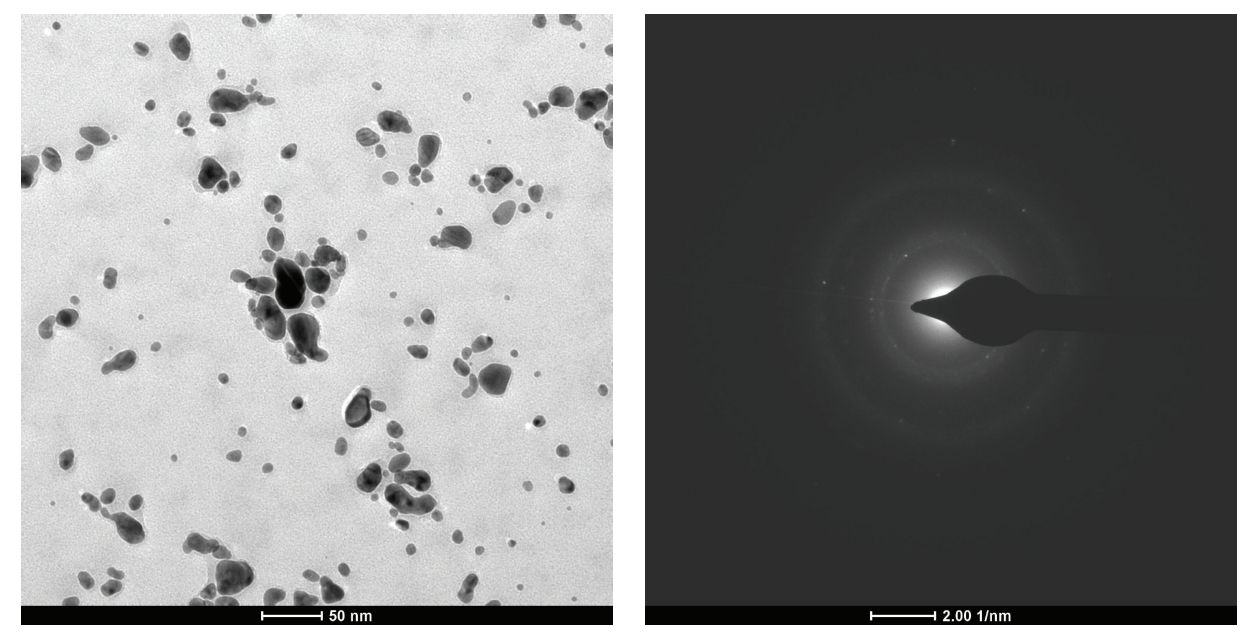

(a)

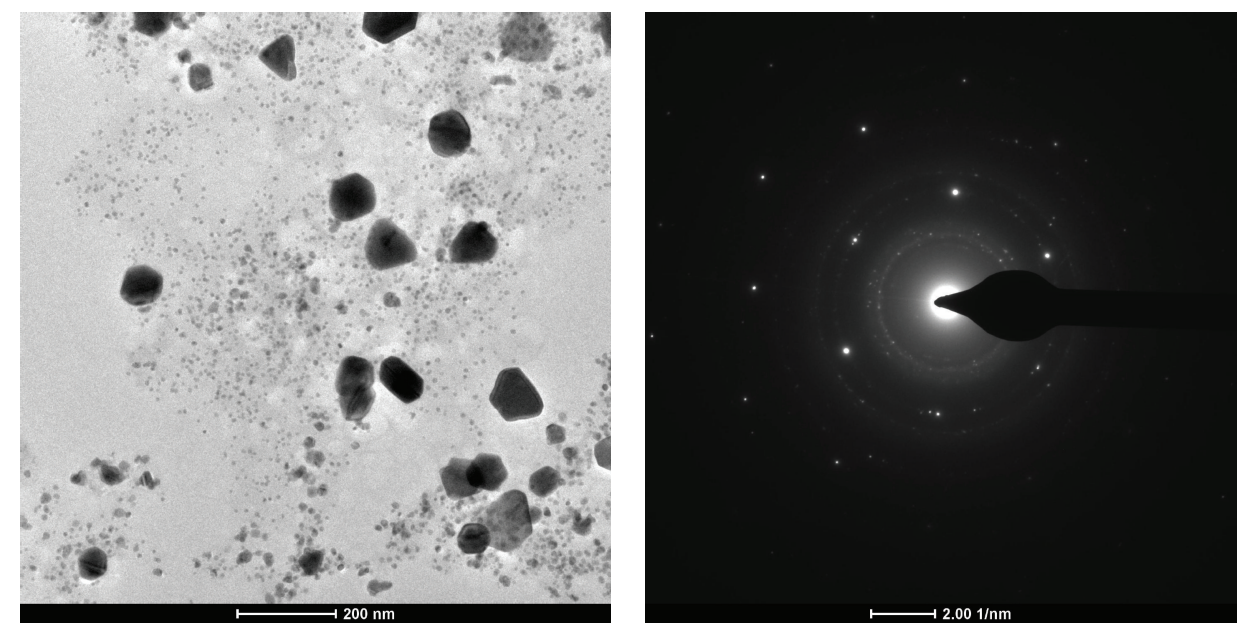

(b)

FIGURE 5: (a) TEM image (left) and SAED pattern (right) of AuNPs synthesized using extract of A. philippense L. (b) TEM image (left) and SAED pattern (right) of AgNPs synthesized using extract of $A$. philippense L.

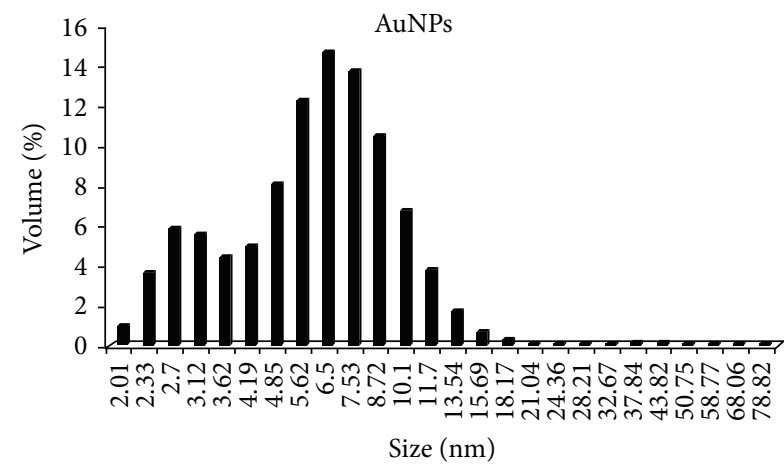

(a)

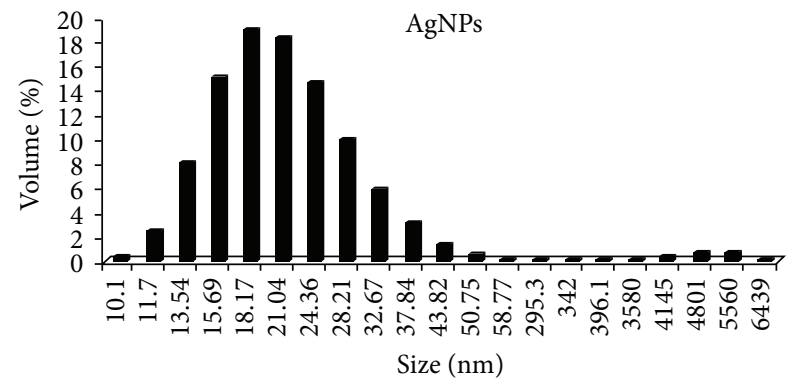

(b)

Figure 6: (a) Histogram of size distribution of AuNPs synthesized by A. philippense L. (b) Histogram of size distribution of AgNPs synthesized by $A$. philippense $\mathrm{L}$. 


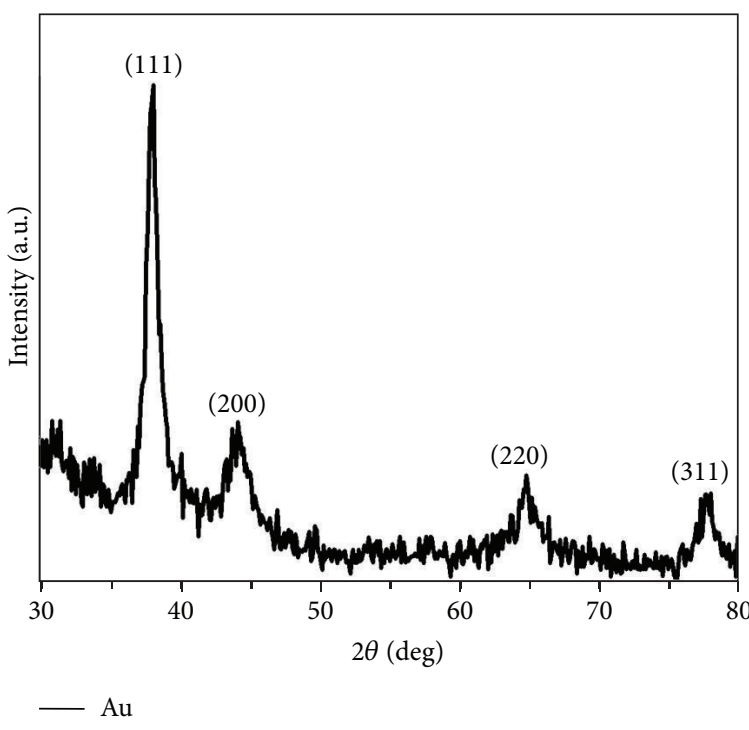

(a)

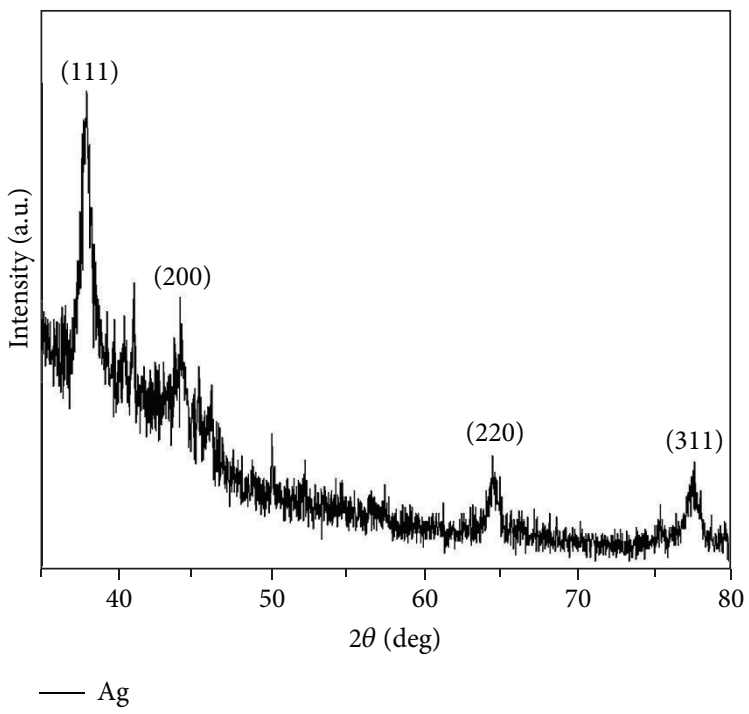

(b)

Figure 7: (a) XRD pattern of AuNPs. (b) XRD pattern of AgNPs.

Earlier reports also indicate that high absorbance and narrow peaks at alkaline $\mathrm{pH}$ favour synthesis of monodispersed and small sized nanoparticles [24]. Alkaline $\mathrm{pH}$ prevents agglomeration of synthesized nanoparticles; therefore, small sized particles are formed $[4,23]$.

Thus, optimum conditions for AuNPs synthesis were 1:1 proportion of original extract at $\mathrm{pH} 11$ and $5 \mathrm{mM}$ tetrachloroauric acid, whereas optimum conditions for AgNPs synthesis were 1:1 proportion of original extract at $\mathrm{pH} 12$ and $9 \mathrm{mM}$ silver nitrate. Time required for nanoparticle synthesis under optimum conditions was checked by reading absorbance in a UV-Vis spectrophotometer and was found to be $10 \mathrm{~min}$ (Figure 4).

3.2. Characterization of AuNPs and AgNPs. Confirmation of AuNPs and AgNPs formation was done by taking UVVis spectrum of the resultant solution, in the range of 200-1000 nm. The spectrum (Figure 4) showed a distinct peak, centered at $530 \mathrm{~nm}$, specific for AuNPs [17]. Similarly, a distinct peak observed at $420 \mathrm{~nm}$ was specific for AgNPs (Figure 4) [18].

The result obtained from the transmission electron microscopy (TEM) and selected area electron diffraction (SAED) study gives clear indication about the shape, size, and size distribution of the nanoparticles. TEM and SAED pattern revealed that AuNPs were anisotropic and polycrystalline in nature (Figure 5(a)). However, TEM and SAED studies in case of AgNPs showed their anisotropic and monocrystalline nature (Figure 5(b)). Particle size analysis of TEM images was done using ImageJ software. Particle size calculated was also confirmed using Scherrer's formula that makes use of XRD data of the samples. Particle size of AuNPs and AgNPs ranged between 10 and $18 \mathrm{~nm}$. This is in agreement with earlier studies reporting nanoparticles of 10 to $100 \mathrm{~nm}$ obtained using various plant extracts $[1,7,23,24]$. Small size of nanoparticles obtained in the present study could be a result of alkaline $\mathrm{pH}$ used for their synthesis $[7,24]$.

Particle size distribution was measured by dynamic light scattering (DLS) (Figures 6(a) and 6(b)). Although the histograms show a significant proportion of nanoparticles lying in the size range as calculated by TEM and XRD analysis, other large agglomerates interfere with the accuracy of particle size determination. These agglomerates could be of biological origin present in the plant extract or could be aggregates of nanoparticles [25]. Das et al. [26] reported that the variation in particle size distribution in DLS $(99.91 \mathrm{~nm})$ as compared to that observed in HRTEM analysis $(15.07 \mathrm{~nm}$ ) could be due to water absorption on electrostatic stabilized gold nanoparticles.

The obtained XRD data was checked against the standard data for the respective samples, provided by the Joint Committee on Powder Diffraction Standards (JCPDS). Both the particles showed face centered cubic (FCC) structure. In case of AuNPs, the data matched with the JCPDS data card number 04-0784, with lattice constant $a=4.078 \AA$. The observed peaks correspond to the planes (111), (200), (220), and (311), respectively, for the peaks in ascending $2 \theta$ order. The results are in agreement with previous reports $[4,8,23,26]$.

The XRD pattern of AgNPs matched with JCPDS data card number 04-0783. Standard lattice constant value for this structure is reported to be $4.086 \AA$. Lattice planes (111), (200), (220), and (311) for AgNPs were also observed in the XRD pattern. Broad peak in both the XRD patterns suggests that the particles size was very less. Crystallite size for both the particles was calculated using Scherrer's formula [27] as

$$
D=\frac{0.9 \lambda}{\beta \cos \theta},
$$




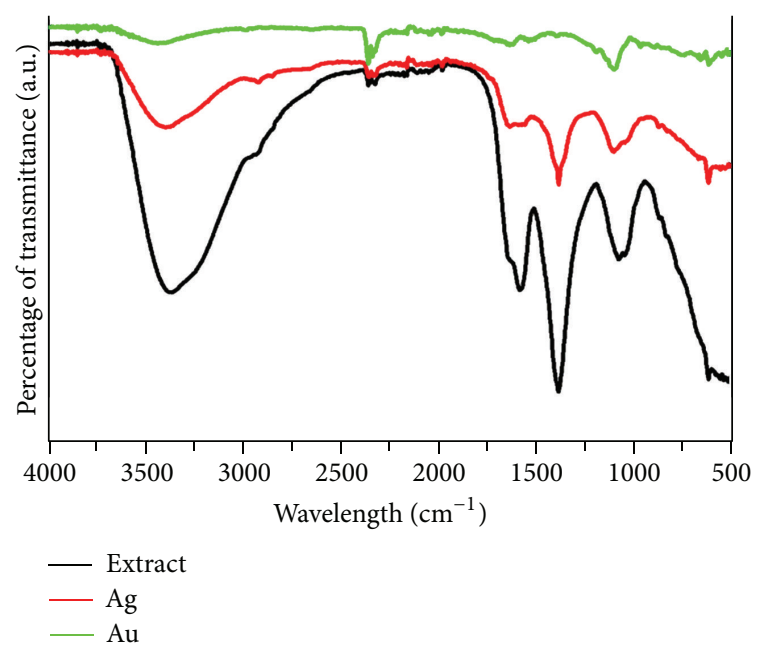

FIgURE 8: FTIR spectra for A. philippense L. extract, the AuNPs, and AgNPs.

where $D$ is particle size, $\lambda$ is wavelength of $\mathrm{X}$-ray, $\beta$ is full width at half maxima for a peak, and $\theta$ is the corresponding Bragg angle. The particle size was estimated to be $\sim 11 \mathrm{~nm}$ for AuNPs and $\sim 13 \mathrm{~nm}$ for AgNPs (Figures 7(a) and 7(b)). This is in good agreement with the particle size obtained from TEM images.

FTIR spectroscopy was carried out to identify the biogroups that bound distinctively on the gold and silver surface and were involved in the synthesis of these nanoparticles. The major peaks observed in FTIR of the extract were 3369, 2360, $1585,1384,1076$, and $514 \mathrm{~cm}^{-1}$. Peak at $3369 \mathrm{~cm}^{-1}$ is attributed to $\mathrm{OH}$ stretch in phenols. This suggests presence of phenolic compound in the extract [28]. Phytochemical evaluation of A. philippense $\mathrm{L}$ also reports the presence of phenols [11, 13]. Taraschewski et al. [29] report that the peak at $2360 \mathrm{~cm}^{-1}$ results due to $\mathrm{CO}_{2}$ vibration that may not be necessarily from the sample. Peaks at 1585,1384 , and $1076 \mathrm{~cm}^{-1}$ are attributed to $\mathrm{C}=\mathrm{C}$ stretching, $-\mathrm{NH}_{2}$ symmetric stretch, and $\mathrm{CO}$ vibrations, respectively. The peak at $514 \mathrm{~cm}^{-1}$ can be attributed to $\mathrm{C}-\mathrm{N}-\mathrm{C}$ bending $[28,30,31]$.

As seen in the case of FTIR for AuNPs, the peak at $1384 \mathrm{~cm}^{-1}$ had completely diminished, while the rest of the peaks from extract were present with reduced intensity. This suggests that the extract might be bound to the AuNPs through or by replacing $-\mathrm{NH}_{2}$ group. In FTIR of AgNPs, the $-\mathrm{NH}_{2}$ peak remained intact while the $\mathrm{C}=\mathrm{C}$ stretching peak almost vanished. This may be due to conjugation of extract to the nanoparticle through $\mathrm{C}=\mathrm{C}$ group (Figure 8). These functional groups of water soluble compounds such as flavonoids, terpenoids, and phenols present in the $A$. philippense L. extract appear to be responsible for synthesis of nanoparticles and their stabilization. Other studies have also reported that proteins or polysaccharides present in the biological material cap and stabilize nanoparticles $[1,17]$. These interactions may occur between free amino groups, carboxylate group, or cysteine residues in the proteins $[1,3$, $6,32]$.

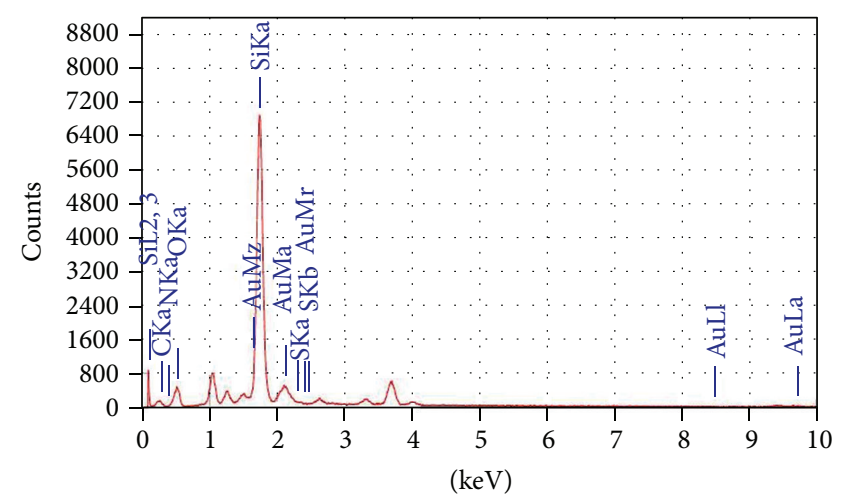

(a)

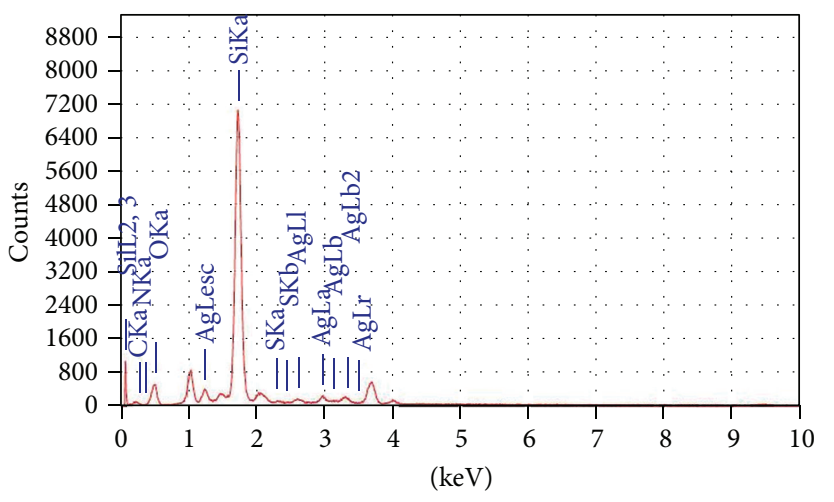

(b)

FIGURE 9: (a) EDS spectrum of AuNPs synthesized using extract of $A$. philippense L. (b) EDS spectrum of AgNPs synthesized using extract of A. philippense L.

Elemental composition of AuNPs and AgNPs and their surrounding was carried out by energy dispersive scattering (EDS). EDS studies for AuNPs and AgNPs showed presence of elemental gold (8.95\%) and silver (5.04\%) (Figures 9(a) and $9(\mathrm{~b})$ ). Detection of carbon and oxygen suggested the presence of carbohydrate compounds containing sulphur that were either capped on AuNPs and AgNPs or were present in the background. Further characterization of the capping agent and its probable involvement in biomedical application needs to be investigated.

\section{Conclusion}

We have developed a method for synthesis of gold and silver nanoparticles using fern A. philippense L., at room temperature, within $10 \mathrm{~min}$. The TEM and EDS analysis results both demonstrate that nanoparticles are successfully synthesized using A. philippense L. extract in this study. To the best of our knowledge, use of pteridophytes in nanoparticles synthesis has not yet been reported. Medicinal importance of ferns makes them a suitable candidate for biosynthesis of nanoparticles and application in disease treatment. Use of such medicinally important plants has a promising potential in nanoscience for drug delivery and biomedical application. Exploitation of synthesized capped nanoparticles would 
enable us to know the nature of capping agent and utilize them for medicinal and biomedical applications.

\section{Conflict of Interests}

The authors declare no conflict of interests.

\section{Acknowledgments}

The authors acknowledge Dr. S. V. Ravat from the Botanical Survey of India, Western Circle, Pune, India, for his help in plant specimen identification, Mr. R. Sridharkrishna from the Department of Physics, University of Pune, and Dr. M. Jayakannan from IISER, Pune, for technical help in material characterization. S. Ghosh thanks Council of Scientific and Industrial Research (CSIR, Government of India) for Senior Research Fellowship (09/137(0516)/2012-EMR-I). The authors also thank DST-PURSE for funding this research.

\section{References}

[1] T. C. Prathna, L. Mathew, N. Chandrasekaran, A. M. Raichur, and A. Mukherjee, Biomimetic Synthesis of Nanoparticles: Science, Technology \& Applicability, Biomimetics Learning from Nature, edited by A. Mukherjee, 2010.

[2] R. R. Arvizo, S. Bhattacharyya, R. Kudgus, K. Giri, R. Bhattacharya, and P. Mukherjee, "Intrinsic therapeutic applications of noble metal nanoparticles: past, present and future," Chemical Society Reviews, vol. 41, no. 7, pp. 2943-2970, 2012.

[3] L. Castro, M. L. Blázquez, F. González, J. A. Muñoz, and A. Ballester, "Extracellular biosynthesis of gold nanoparticles using sugar beet pulp," Chemical Engineering Journal, vol. 164, pp. 9297, 2010.

[4] A. D. Dwivedi and K. Gopal, "Biosynthesis of silver and gold nanoparticles using Chenopodium album leaf extract," Colloids and Surfaces A, vol. 369, no. 1-3, pp. 27-33, 2010.

[5] S. Ghosh, S. Patil, M. Ahire et al., "Synthesis of silver nanoparticles using Dioscorea bulbifera tuber extract and evaluation of its synergistic potential in combination with antimicrobial agents," International Journal of Nanomedicine, vol. 7, pp. 483-496, 2012.

[6] D. Philip, "Biosynthesis of $\mathrm{Au}, \mathrm{Ag}$ and $\mathrm{Au}-\mathrm{Ag}$ nanoparticles using edible mushroom extract," Spectrochimica Acta Part A, vol. 73, pp. 374-381, 2009.

[7] M. Sathishkumar, K. Sneha, S. W. Won, C. W. Cho, S. Kim, and Y. S. Yun, "Cinnamon zeylanicum bark extract and powder mediated green synthesis of nano-crystalline silver particles and its bactericidal activity," Colloids and Surfaces B, vol. 73, no. 2, pp. 332-338, 2009.

[8] S. Kaviya, J. Santhanalakshmi, B. Viswanathan, J. Muthumary, and K. Srinivasan, "Biosynthesis of silver nanoparticles using citrus sinensis peel extract and its antibacterial activity," Spectrochimica Acta Part A, vol. 79, no. 3, pp. 594-598, 2011.

[9] O. Sawant, V. J. Kadam, and R. Ghosh, "In vitro free radical scavenging and antioxidant activity of Adiantum lunulatum," Journal of Herbal Medicine and Toxicology, vol. 3, no. 2, pp. 3944, 2009.

[10] V. Karthik, K. Raju, M. Ayyanar, K. Gowrishankar, and T. Sekar, "Ethno medicinal uses of pteridophytes in Kolli Hills, Eastern Ghats of Tamil Nadu, India," Journal of Natural Product and Plant Resources, vol. 1, no. 2, pp. 50-55, 2011.
[11] C. Pan, Y. G. Chen, X. Y. Ma, J. H. Jiang, F. He, and Y. Zhang, "Phytochemical constituents and pharmacological activities of plants from the Genus Adiantum: a review," Tropical Journal of Pharmaceutical Research, vol. 10, no. 5, pp. 681-692, 2011.

[12] M. J. Mithraja, J. M. Antonisamy, M. Mahesh, Z. M. Paul, and S. Jeeva, "Inter-specific variation studies on the phytoconstituents of Christella and Adiantum using phytochemical methods," Asian Pacific Journal of Tropical Biomedicine, vol. 2, no. 1, pp. 40-45, 2012.

[13] M. S. Ali, M. R. Amin, C. M. I. Kamal, and M. A. Hossain, "In vitro antioxidant, cytotoxic, thrombolytic activities and phytochemical evaluation of methanol extract of the A. philippense L. leaves," Asian Pacific Journal of Tropical Biomedicine, vol. 3, no. 6, pp. 464-469, 2013.

[14] S. Ghosh, S. Patil, M. Ahire et al., "Gnidia glauca flower extract mediated synthesis of gold nanoparticles and evaluation of its chemocatalytic potential," Journal of Nanobiotechnology, vol. 10, no. 17, 2012.

[15] S. Ghosh, S. Patil, M. Ahire et al., "Synthesis of gold nanoanisotrops using Dioscorea bulbifera tuber extract," Journal of Nanomaterials, vol. 2011, Article ID 354793, 8 pages, 2011.

[16] Y. Park, Y. N. Hong, A. Weyers, Y. S. Kim, and R. J. Linhardt, "Polysaccharides and phytochemicals: a natural reservoir for the green synthesis of gold and silver nanoparticles," IET Nanobiotechnology, vol. 5, no. 3, pp. 69-78, 2011.

[17] K. Govindaraju, S. K. Basha, V. G. Kumar, and G. Singaravelu, "Silver, gold and bimetallic nanoparticles production using single-cell protein (Spirulina platensis) Geitler," Journal of Materials Science, vol. 43, no. 15, pp. 5115-5122, 2008.

[18] R. Vaidyanathan, K. Kalishwaralal, S. Gopalram, and S. Gurunathan, "Nanosilver-the burgeoning therapeutic molecule and its green synthesis," Biotechnology Advances, vol. 27, no. 6, pp. 924-937, 2009.

[19] S. S. Shankar, A. Rai, B. Ankamwar, A. Singh, A. Ahmad, and M. Sastry, "Biological synthesis of triangular gold nanoprisms," Nature Materials, vol. 3, no. 7, pp. 482-488, 2004.

[20] S. S. Shankar, A. Rai, A. Ahmad, and M. Sastry, "Controling the optical properties of lemongrass extract synthesized gold nanotriangles and potebtial application in infrared absorbing optical coatings," Applied Nanoscience, vol. 1, pp. 69-77, 2005.

[21] D. S. Sheny, J. Mathew, and D. Philip, "Phytosynthesis of Au, Ag and $\mathrm{Au}-\mathrm{Ag}$ bimetallic nanoparticles using aqueous extract and dried leaf of Anacardium occidentale," Spectrochimica Acta Part A, vol. 79, no. 1, pp. 254-262, 2011.

[22] K. D. Arunachalam, S. K. Annamalai, and S. Hari, “One-step green synthesis and characterization of leaf extract-mediated biocompatible silver and gold nanoparticles from Memecylon umbellatum," International Journal of Nanomedicine, vol. 8, pp. 307-1315, 2013.

[23] S. P. Dubey, M. Lahtinen, and M. Sillanpää, "Tansy fruit mediated greener synthesis of silver and gold nanoparticles," Process Biochemistry, vol. 45, no. 7, pp. 1065-1071, 2010.

[24] T. P. Amaladhas, S. Sivagami, T. A. Devi, N. Ananthi, and S. P. Velammal, "Biogenic synthesis of silver nanoparticles by leaf extract of Cassia angustifolia," Advances in Natural Sciences, vol. 3, pp. 1-8, 2012.

[25] A. Bootz, V. Vogel, D. Schubert, and J. Kreuter, "Comparison of scanning electron microscopy, dynamic light scattering and analytical ultracentrifugation for the sizing of poly(butyl cyanoacrylate) nanoparticles," European Journal of Pharmaceutics and Biopharmaceutics, vol. 57, no. 2, pp. 369-375, 2004. 
[26] S. Das, P. Roy, S. Mondal, T. Bera, and A. Mukherjee, "One pot synthesis of gold nanoparticles and application in chemotherapy of wild and resistant type visceral leishmaniasis," Colloids and Surfaces B, vol. 107, pp. 27-34, 2013.

[27] R. Parmar, M. H. Mangrola, B. H. Parmar, and V. G. Joshi, "A software to calculate crystalline size by Debey-Scherrer Formula using VB.NET,' Multi Disciplinary Edu Global Quest, vol. 1, no. 1, 2012.

[28] R. Silverstein and F. Webster, Spectrometric Identification of Organic Compounds, Wiley India, 6th edition, 2006.

[29] M. Taraschewski, H. K. Cammenga, R. Tuckermann, and S. Bauerecker, "FTIR Study of $\mathrm{CO}_{2}$ and $\mathrm{H}_{2} \mathrm{O} / \mathrm{CO}_{2}$ nanoparticles and their temporal evolution at $80 \mathrm{~K}$," Journal of Physical Chemistry A, vol. 109, no. 15, pp. 3337-3343, 2005.

[30] C. Y. Kim, T. Sekino, and K. Niihara, "Synthesis of bismuth sodium titanate nanosized powders by solution/sol-gel process," Journal of the American Ceramic Society, vol. 86, no. 9, pp. 14641467, 2003.

[31] Y. F. Zhang, J. X. Zhang, Q. M. Lu, and Q. Y. Zhang, "Synthesis and characterization of $\mathrm{Ca}_{3} \mathrm{Co}_{4} \mathrm{O}_{9}$ nanoparticles by citrate solgel method," Materials Letters, vol. 60, no. 20, pp. 2443-2446, 2006.

[32] S. P. Chandran, M. Chaudhary, R. Pasricha, A. Ahmad, and M. Sastry, "Synthesis of gold nanotriangles and silver nanoparticles using Aloe vera plant extract," Biotechnology Progress, vol. 22, no. 2, pp. 577-583, 2006. 

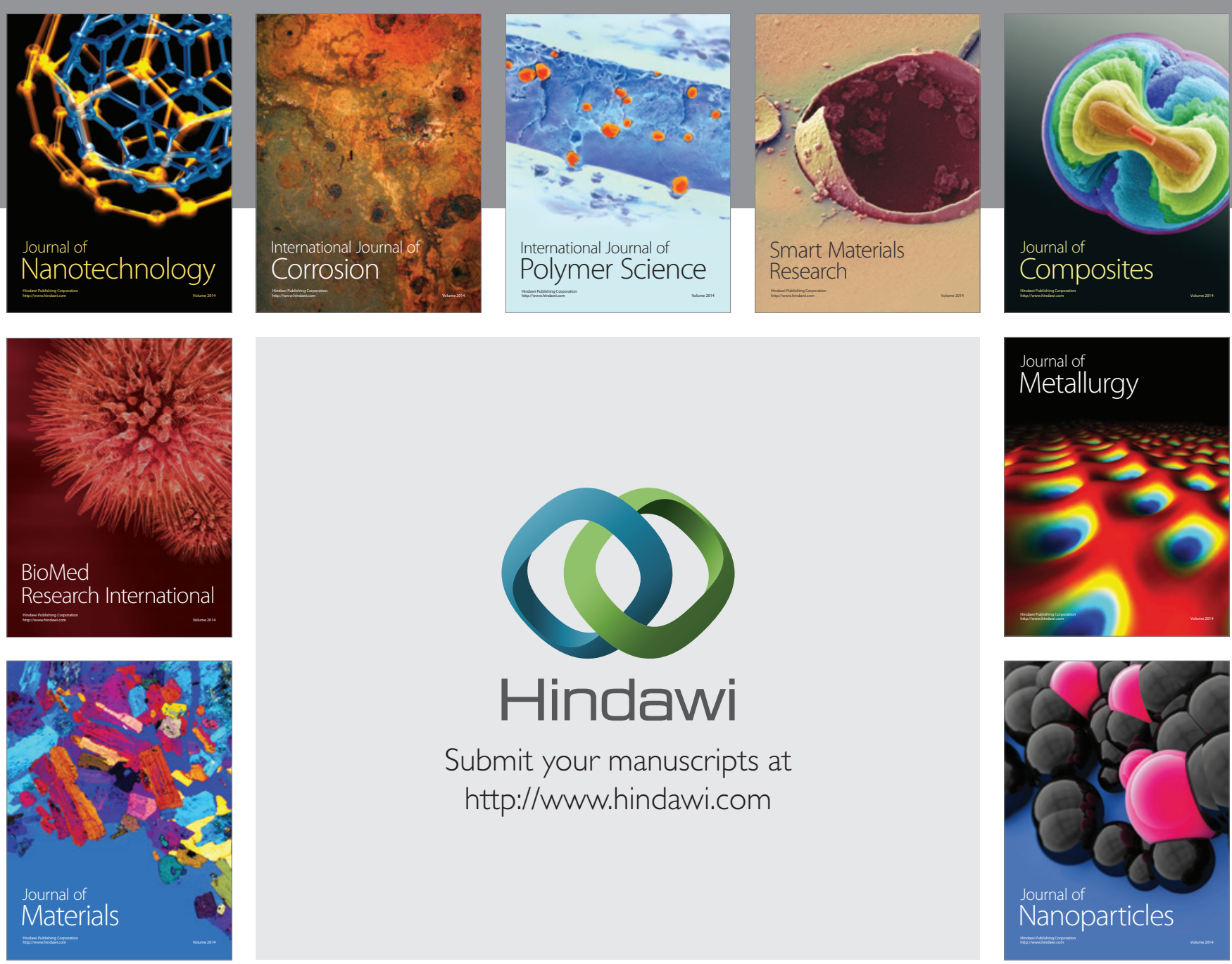

Submit your manuscripts at http://www.hindawi.com
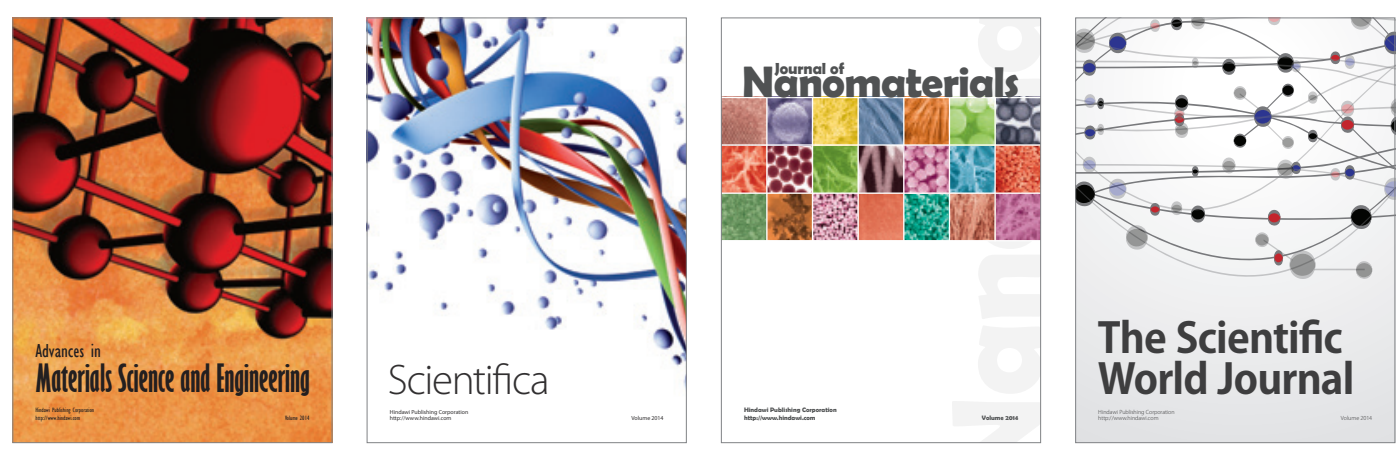

\section{The Scientific World Journal}
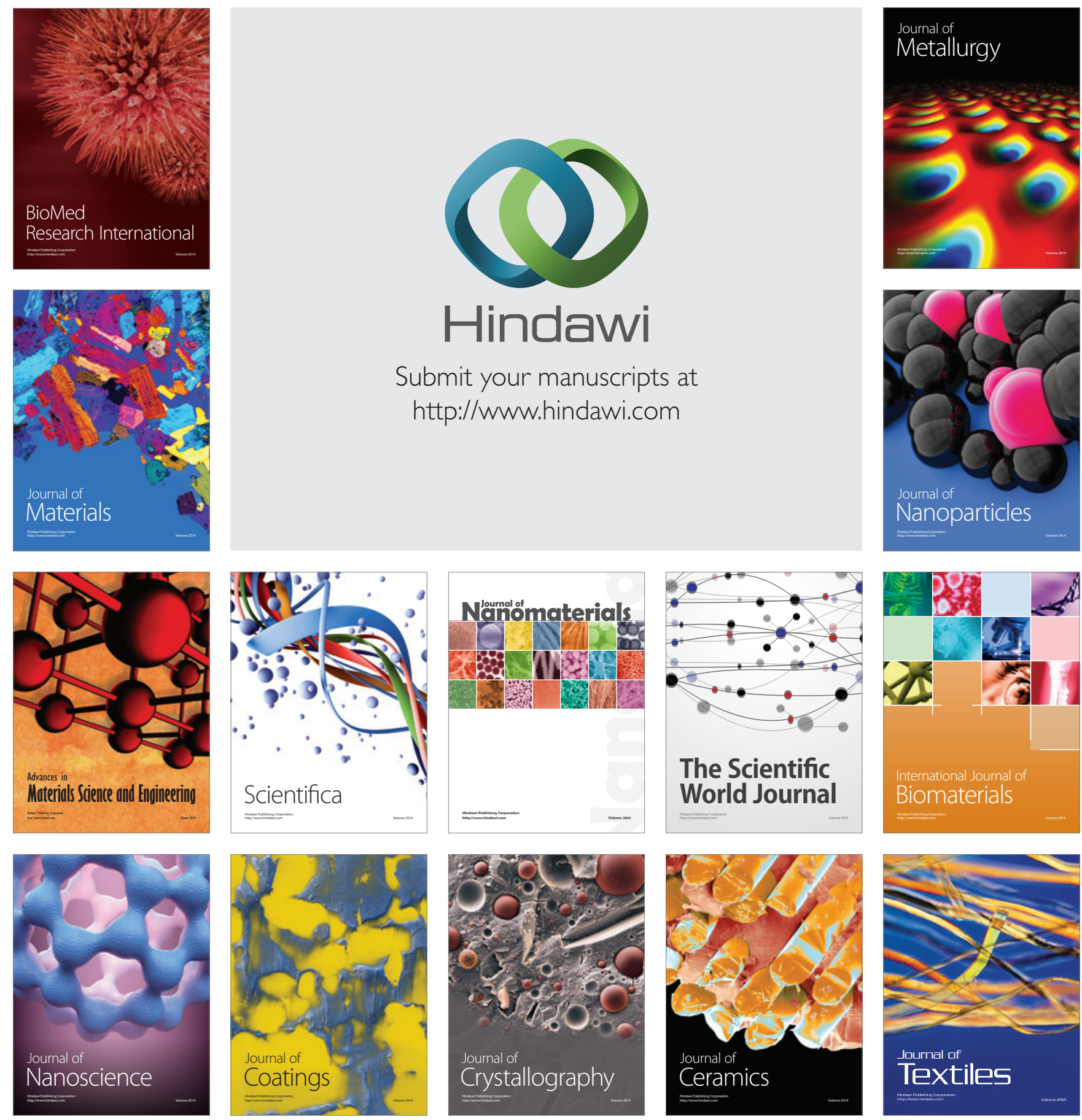